\title{
Corrosion inhibition properties of Gongronema latifollium extract in acidic media
}

\author{
C.O. Akalezi, ${ }^{1 *}$ C.E. Ogukwe, ${ }^{1}$ E.A. Ejele $^{2}$ and E.E. Oguzie ${ }^{1}$ \\ ${ }^{I}$ Electrochemical and Material Science Unit (EMRU), Department of Chemistry, School of \\ Sciences, Federal University of Technology Owerri, Nigeria \\ ${ }^{2}$ Department of Chemistry; School of Physical Sciences, \\ Federal University of Technology Owerri, Nigeria \\ *E-mail: chrisakalezi@yahoo.com
}

\begin{abstract}
Corrosion inhibition of mild steel in $1 \mathrm{M} \mathrm{HCl}$ acid solution by Gongronemena latifolium (GL) extract was investigated by weight-loss and electrochemical techniques. A significant decrease in the corrosion rate of mild steel was observed in the presence of the investigated additive and the inhibition efficiency was found to depend on the concentration of the GL extract. The potentiodynamic polarization data indicated that this additive was of mixed type, but the anodic effect was more pronounced. Nyquist plots showed that on increasing the extract concentration, the charge transfer resistance increased and double layer capacitance decreased. Adsorption of inhibitor GL extract on the mild steel surface is found to obey the Langmuir adsorption isotherm. Increase in activation energy of corrosion process in presence of GL extract indicates physical adsorption.
\end{abstract}

Key words: Gongronemena latifolium, mild steel, corrosion inhibition, hydrochloric acid. Received: April 8, 2016. Published: July 4, 2016.

doi: 10.17675/2305-6894-2016-5-3-4

\section{Introduction}

A huge amount of $\mathrm{HCl}$ is used in the chemical industry for removal of undesired scales and rust. The addition of corrosion inhibitors effectively secures the metal against an acid attack. Many studies in this regard using organic inhibitors have been reported $[1-5]$. Generally, synthetic organic compounds containing hetero atoms like $\mathrm{O}, \mathrm{N}$ and $\mathrm{S}$ are normally found to have higher basic properties and electron density, which make them the reaction centers. These compounds are adsorbed on the metallic surface and block the active corrosion sites with high efficiency. Despite the high efficiency of these commonly used synthetic compounds, they are often toxic, carcinogenic or even allergenic. Thus there has been emerging need to search for biodegradable, environmentally friendly inhibitors obtained from renewable resources with minimal health and safety concerns [6-15].

Plant extracts are biodegradable and constitute incredibly rich sources of natural chemical compounds that can be extracted by simple procedures at low cost [16]. The basic 
components of extracts are sugars, gallic acid, ellagic acid, and flavonoids; even the presence of tannins, cellulose, and polycyclic compounds normally enhances the film formation over the metal surface, thus decreasing corrosion $[17,18]$. Comparisons have been made over the years between the toxic inhibitors, like chromates and other organic inhibitors, and the natural inhibitors and it has been observed that the natural inhibitors could serve as an effective substitute for the currently preferred organic inhibitors [19-22].

Gongronema latifolium is a tropical rainforest plant primarily used as spice and vegetable in South Western and South Eastern parts of Nigeria [23]. Reports by various authors [24-26] showed that it contains essential oils, saponins and pregnanes among others. Ugochukwu et al. [27] and Ogundipe et al. [28] reported that aqueous and ethanolic GL extracts had hypoglycemic, hypolipidemic and antioxidative properties. These reports are focused mainly on the medicinal properties of the plant.

In the present work the corrosion inhibition properties of ethanolic GL extracts on corrosion behaviour of mild steel in $1 \mathrm{M} \mathrm{HCl}$ solution was investigated using gravimetric and electrochemical techniques. The necessary gas chromatography-mass spectrometry (GC-MS) of the ethanol extract was obtained to enable identification of the active constituents.

\section{MATERIALS AND METHODS}

\subsection{Inhibitor Preparation}

About $80 \mathrm{~g}$ of sun dried powdered leaves of GL was taken in a Soxhlet extractor with $400 \mathrm{~mL}$ of ethanol and continuously refluxed for $6 \mathrm{~h}$. The extract was filtered using Whatmann No.1 filter paper. The liquid extract was concentrated by evaporating the solvent to dryness on a water bath to obtain a gel. The weight of the extract is taken and kept at $4{ }^{\circ} \mathrm{C}$ prior to use. The aqueous plant extract solution was used for analyzing the phytoconstituents. Also from the crude extract various inhibitor concentrations ranging from $50 \mathrm{mg} / \mathrm{L}$ to $100 \mathrm{mg} / \mathrm{L}$ was prepared and used to evaluate the corrosion inhibition efficacy.

The aggressive solutions $(1 \mathrm{M} \mathrm{HCl})$ were prepared by dilution of analytical grade $\mathrm{HCl}$ with double distilled water

\subsection{Phytochemical screening}

Phytochemical screening was performed using standard procedure [29-31].

\subsection{Gas Chromatography-mass spectrometry analysis}

The Gas chromatography-Mass spectrometry (GC-MS) analysis of the extract was performed using a GC-MS Model; QP 2010 PLUS series, equipped with a VF-5ms fused silica capillary column of $80 \mathrm{~m}$ length, $0.25 \mathrm{~mm}$ diameter and $0.25 \mu \mathrm{m}$ film thickness. For GC-MS detection, an electron ionization system, ionization energy of $70 \mathrm{eV}$ was used. 
Helium gas (99.99\%) was used as a carrier gas at a constant flow rate of $1.51 \mathrm{ml} / \mathrm{min}$. Injector and mass transfer line temperature were set at 230 and $250^{\circ} \mathrm{C}$ respectively. The oven temperature was programmed from 80 to $200^{\circ} \mathrm{C}$ at $10^{\circ} \mathrm{C} / \mathrm{min}$, held isothermal for $1 \mathrm{~min}$ and finally raised to $280^{\circ} \mathrm{C}$ at $10^{\circ} \mathrm{C} / \mathrm{min} .2 \mu \mathrm{l}$ of respective dilute sample was manually injected in the split less mode, with split ratio of 1:40 and with the mass scan of $40-600 \mathrm{~m} / z$. Total running time of GC-MS is $27 \mathrm{~min}$. The relative percentage of the extract constituents was expressed as percentage with peak area normalization.

\subsection{Specimen preparation}

Working electrodes were prepared from mild steel (MS) specimens with a composition (wt. \%) of C: $0.17-0.24, \mathrm{P}: 0.04, \mathrm{Mn}: 0.30-0.60, \mathrm{~S}: 0.05$ and Fe: balance. Coupons cut with $4.0 \mathrm{~cm} \times 4.0 \mathrm{~cm} \times 0.15 \mathrm{~cm}$ dimensions were used for weight loss measurements, whereas specimens prepared by embedding steel rods in epoxy resin with exposed surface area of $1 \mathrm{~cm}^{2}$, were used as working electrodes for polarization and EIS measurements. The exposed area was mechanically abraded with 400, 500 and 600 grade emery paper, washed with double-distilled water, degreased with acetone and finally dried before each experiment.

\subsection{Weight loss method}

Pre-weighed MS specimens were suspended in $200 \mathrm{~mL}$ of the acid solution $(1 \mathrm{M} \mathrm{HCl})$ without and with the different concentrations GL extract ranging from 50 to $1000 \mathrm{mg} / \mathrm{L}$. The duration of the immersion was $24 \mathrm{~h}$ at temperature $303 \mathrm{~K}$ and $3 \mathrm{~h}$ at temperatures from 313 to $333 \mathrm{~K}$. After the specified time the coupons were removed from test solution, thoroughly washed with $\mathrm{NaHCO}_{3}$ solution and de-ionized water, dried well and then weighed. The experiments were done in triplicate and the average value of the weight loss was noted. The inhibition efficiency (IE\%) was determined by using following equation:

$$
\mathrm{IE}(\%)=\frac{w_{0}-w_{i}}{w_{0}} \times 100,
$$

where $w_{i}$ and $w_{0}$ are the weight loss values in the presence and absence of inhibitor, respectively.

\subsection{Electrochemical procedure}

The electrochemical experiments were carried out using a conventional three-electrode cylindrical glass cell at a temperature of $303 \mathrm{~K} \pm 2 \mathrm{~K}$. The MS of $1 \mathrm{~cm}^{2}$ was the working electrode; a saturated calomel electrode (SCE) and a graphite rod were used as the reference and auxiliary electrodes, respectively. The working electrode was abraded with different grades of emery papers, washed with water and degreased with acetone. All electrochemical measurements were performed using a Potentiostat/Galvanostat (VERSASTAT 400), K0047 model corrosion system with V3 studio software. Before each 
experiment, the electrode was allowed to corrode freely, and its open circuit potential (OCP) was recorded as a function of time up to $1 \mathrm{~h}$. Electrochemical impedance measurements were carried out using AC signals of $10 \mathrm{mV}$ amplitude peak-to-peak in the frequency range of $1000 \mathrm{kHz}-10 \mathrm{MHz}$. The impedance diagrams are given in the Nyquist representation. The charge transfer resistance values were obtained from the diameter of the semi-circles of the Nyquist plots. The inhibition efficiency and surface coverage $(\theta)$ of the inhibitor was calculated from the charge transfer resistance values using the following relationship:

$$
\mathrm{IE}_{\mathrm{R}} \%=\left(\frac{R_{\mathrm{ct}(\mathrm{inh})}-R_{\mathrm{ct}}}{R_{\mathrm{ct}(\mathrm{inh})}}\right) \times 100,
$$

where $R_{\mathrm{ct}(\mathrm{inh})}$ and $R_{\mathrm{ct}}$ are the values of the charge transfer resistance at the mild steel with and without the GL extract respectively. Tafel curves were obtained by changing the electrode potential automatically from $\pm 250 \mathrm{mV}$ versus OCP at a scan rate of $0.333 \mathrm{mV} \mathrm{s}^{-1}$. The above procedures were repeated for each concentration of inhibitor. The linear Tafel segments of anodic and cathodic curves were extrapolated to corrosion potential to obtain corrosion current densities $\left(I_{\text {corr }}\right)$. The inhibition efficiency $(\mathrm{IE} \%)$ was calculated as follows:

$$
\mathrm{IE} \%=\frac{I_{0}-I_{\mathrm{i}}}{I_{0}} \times 100,
$$

where $I_{0}$ and $I_{\mathrm{i}}$ are the corrosion current in absence and in presence of inhibitor, respectively.

\section{RESULTS AND DISCUSSION}

\subsection{Phytochemical screening of plant material and GC-MS study:}

The data from this study revealed that this vegetable extract has a rich content of phytochemicals, namely, saponins, flavonoids, resins, terpenoids, steroids, glycosides carbohydrates, proteins, fats and oils [29-31]. These active constituents are responsible for the inhibition efficiency of the extract $[32,33]$.

The GC separated compounds are identified from the recorded mass spectra by comparison with the mass spectra from the database of National Institute of Standard Technology (NIST) library. GC-MS chromatogram of the ethanolic extract of GL showed 8 prominent peaks as shown in Figure 1. The 8 active constituents with their retention time (RT), molecular formula, molecular weight (MW) and peak area (\%) in the ethanolic extract of GL are presented in Table 1. 


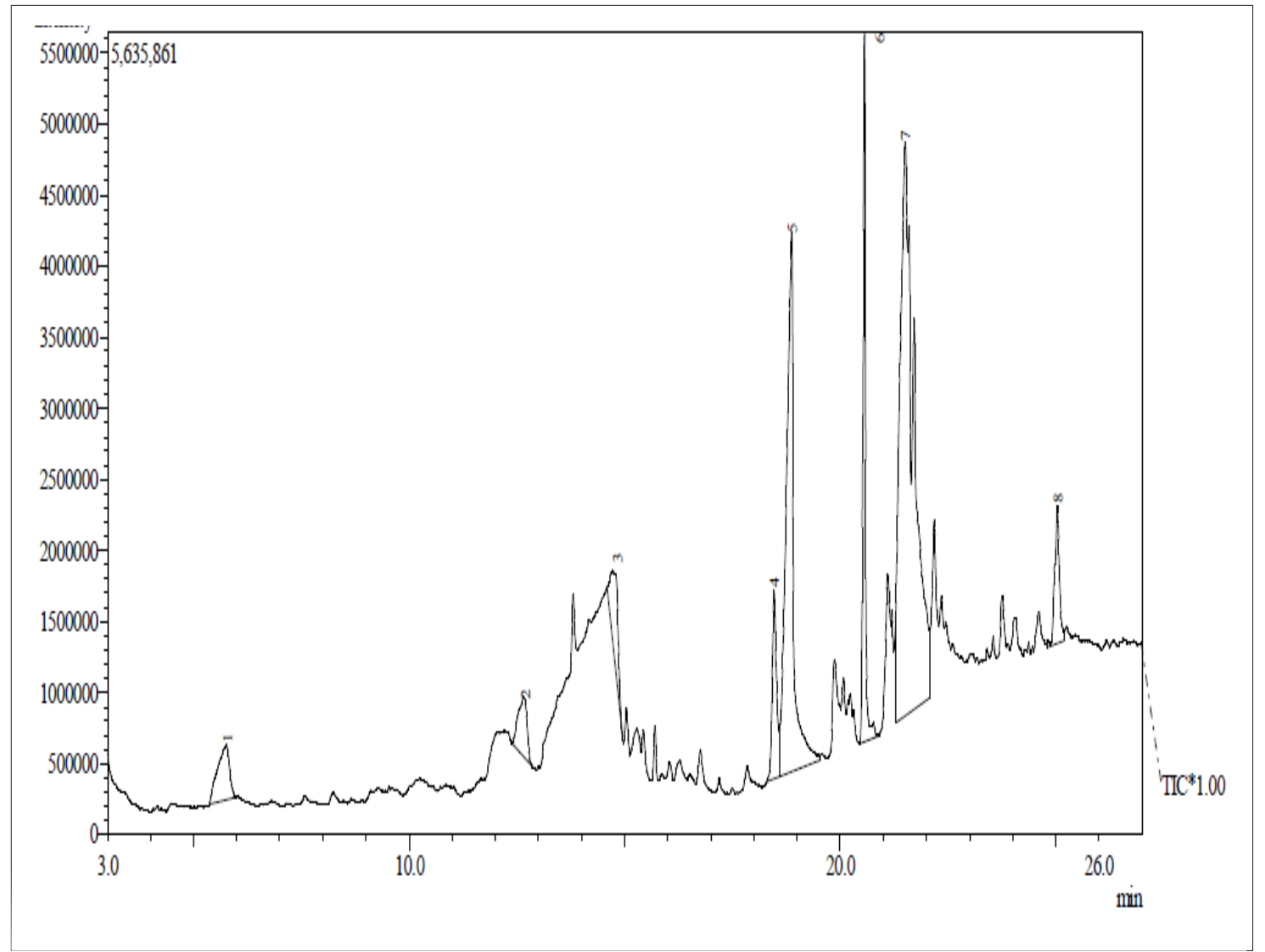

Figure 1. Gas chromatography-mass spectra of GL extract.

Table 1. Phytochemical components identified from the ethanolic extract of GL leaves by GC-MS.

\begin{tabular}{|c|c|c|c|c|c|}
\hline $\begin{array}{c}\text { Peak } \\
\text { number }\end{array}$ & $\begin{array}{l}\text { Retention } \\
\text { time }\end{array}$ & Name of Compound & $\begin{array}{l}\text { Molecular } \\
\text { formula }\end{array}$ & $\begin{array}{l}\text { Molecular } \\
\text { weight }\end{array}$ & Peak area \\
\hline 1 & 5.766 & 1,2,3- propanetriol & $\mathrm{C}_{3} \mathrm{H}_{8} \mathrm{O}_{8}$ & 92 & 3.79 \\
\hline 2 & 12.656 & 1,2,3,4-Cyclohexanetriol & $\mathrm{C}_{6} \mathrm{H}_{12} \mathrm{O}_{4}$ & 148 & 3.02 \\
\hline 3 & 14.715 & $\begin{array}{l}\text { Isopropyl-2,3-dideoxyhex- } \\
\text { 2-enopyranoside }\end{array}$ & $\mathrm{C}_{9} \mathrm{H}_{16} \mathrm{O}_{4}$ & 188 & 4.69 \\
\hline 4 & 18.468 & $\begin{array}{l}\text { Methyl 12- } \\
\text { methyltetradecanoate }\end{array}$ & $\mathrm{C}_{16} \mathrm{H}_{32} \mathrm{O}_{2}$ & 256 & 3.64 \\
\hline 5 & 18.880 & $\begin{array}{l}\text { 1-Pentadecane } \\
\text { carboxylic acid }\end{array}$ & $\mathrm{C}_{16} \mathrm{H}_{32} \mathrm{O}_{2}$ & 256 & 23.42 \\
\hline 6 & 20.568 & Trans-phytol & $\mathrm{C}_{20} \mathrm{H}_{40} \mathrm{O}$ & 296 & 10.51 \\
\hline 7 & 21.518 & cis-Oleic acid & $\mathrm{C}_{18} \mathrm{H}_{34} \mathrm{O}_{2}$ & 282 & 47.14 \\
\hline 8 & 25.047 & $\begin{array}{l}\text { Methyl }(Z)-5,11,14,17- \\
\text { eicosatetraenoate }\end{array}$ & $\mathrm{C}_{12} \mathrm{H}_{34} \mathrm{O}_{2}$ & 318 & 3.79 \\
\hline
\end{tabular}




\subsection{Gravimetric Studies}

Table 2 represents the corrosion parameters obtained by weight loss method during the corrosion of MS in $1 \mathrm{M} \mathrm{HCl}$ medium containing different concentrations of GL extract at $303 \mathrm{~K}$ for $24 \mathrm{~h}$ immersion period. The inhibition efficiency (IE\%) was found to increase with increase in the concentration of the extract reaching a maximum of $91.00 \%$ at $1000 \mathrm{mg} / \mathrm{L}$ concentration. From the values of IE\% it is evident that the corrosion inhibition may be due to adsorption of the plant constituents on the metal surface. The adsorption of the phytoconstituents on the metal surface makes a barrier for mass and charge transfers thus protecting the metal surface from corrosion. The degree of protection increases with the increasing surface fraction occupied by the adsorbed molecules.

Table 2. Corrosion rate of mild in $1 \mathrm{M} \mathrm{HCl}$ solution without and with different concentrations of GL extract for $24 \mathrm{~h}$ at $303 \mathrm{~K}$.

\begin{tabular}{cccc}
\hline Inhibitor $(\mathbf{m g} / \mathbf{l})$ & $\begin{array}{c}\text { Average weight-loss } \\
\boldsymbol{\Delta ( \mathbf { g } )}\end{array}$ & $\begin{array}{c}\text { Corrosion rate } \\
\mathbf{m g} /\left(\mathbf{c m}^{\mathbf{2}} \mathbf{h}\right)\end{array}$ & $\begin{array}{c}\text { Inhibition efficiency } \\
\mathbf{( \% )}\end{array}$ \\
\hline Blank & 0.1285 & 0.280 & \\
50 & 0.0339 & 0.074 & 73.62 \\
200 & 0.0194 & 0.042 & 84.90 \\
400 & 0.0149 & 0.033 & 88.40 \\
600 & 0.0147 & 0.032 & 88.56 \\
800 & 0.0138 & 0.030 & 89.46 \\
1000 & 0.0120 & 0.026 & 90.66 \\
\hline
\end{tabular}

\subsection{Electrochemical measurements}

\subsubsection{Electrochemical impedance spectroscopy (EIS)}

The corrosion of MS in $1 \mathrm{M} \mathrm{HCl}$ solution in the presence of GL extract was investigated by EIS at $303 \mathrm{~K}$ after an exposure period of $1 \mathrm{~h}$ at OCP. Nyquist plots for mild steel obtained at the interface in the absence and presence of various concentrations of GL extract is given in Figure 2. The Nyquist plots shows semicircles with single capacitive loop and increasing diameter as the concentration of the plant extract increases. Deviations from a perfect circular shape indicate frequency dispersion of interfacial impedance arising from lack of homogeneity of the electrode surface due to roughness or interfacial phenomenon $[34,35]$. That is why the pure capacitance is substituted by a Constant Phase Element (CPE), i.e., a model element of frequency distributed behavior is introduced to the structural model illustrated in Figure 3. CPE summarizes the impedance answer of the distribution process in a single expression given by [36]: 


$$
Z_{\mathrm{CPE}}=\frac{1}{A}(j \omega)^{-n},
$$

where $Z_{\mathrm{CPE}}$, impedance of CPE, $A$ is the CPE constant, $\omega$ is the angular frequency, $j$ is the imaginary unit $(-1)^{1 / 2}$, while $n$ has the meaning of a phase shift. CPE has pure capacitance behavior in case $n=1$. The dispersion of the capacitance semicircle is usually connected with surface inhomogeneity, active centers distribution, inhibitor adsorption, formation of porous layers, etc. [36-39].

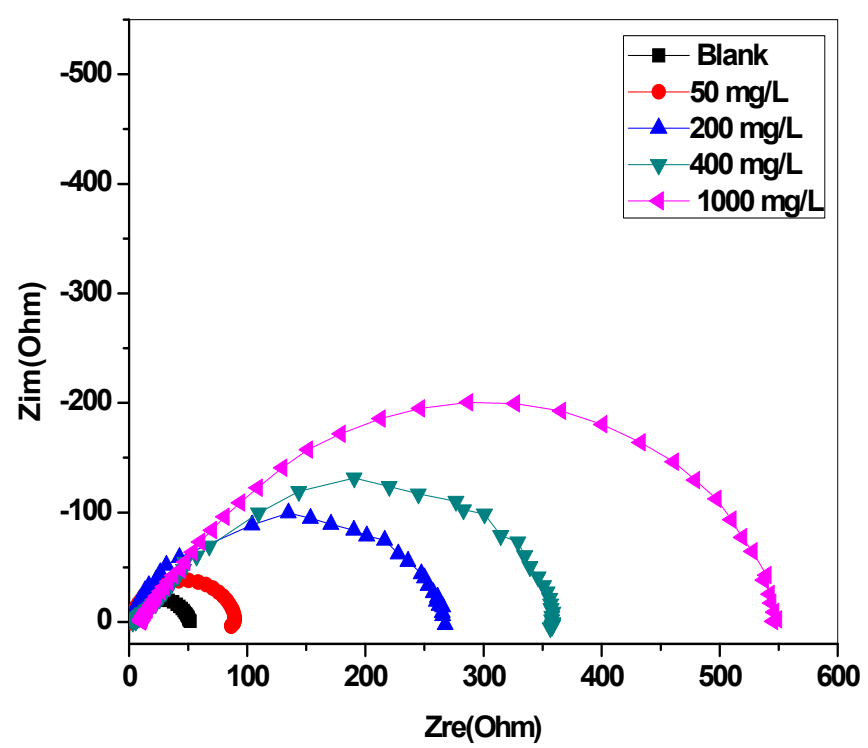

Figure 2. Electrochemical impedance spectra (Nyquist plots) of mild steel in $1 \mathrm{M} \mathrm{HCl}$ solution at $303 \mathrm{~K}$ without and with GL extract.

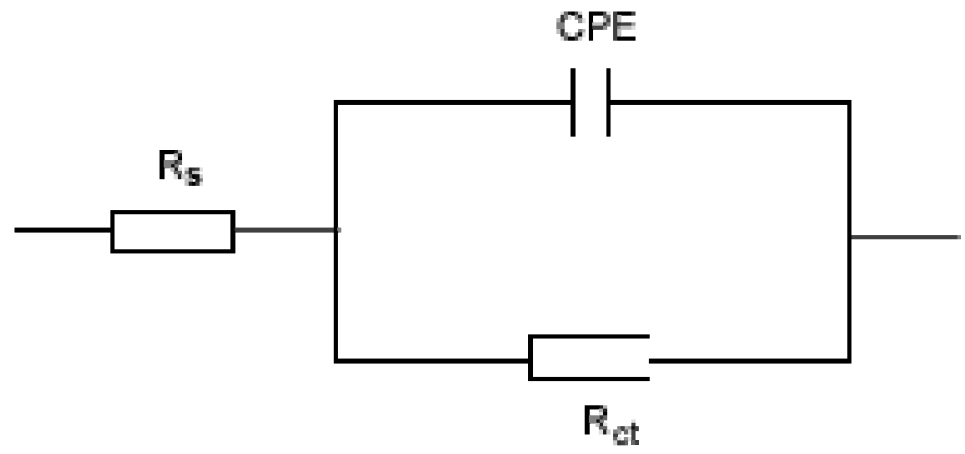

Figure 3. Equivalent circuit model represents the metal/solution interface, $\mathrm{CPE}$, constant phase element; $R_{\mathrm{ct}}$, charge transfer resistance; $R_{\mathrm{S}}$, solution resistance. 
The capacitance values of the electrical double layer were calculated according to the following equation $[40,41]$ :

$$
C_{\mathrm{dl}}=\left(A R_{\mathrm{ct}}^{1-n}\right)^{\frac{1}{n}}
$$

where $A$ is the magnitude of CPE, $R_{\mathrm{ct}}$ is the charge transfer resistance, and $n$ is the CPE exponent. Simulation of Nyquist plots with Randle's model (Figure 3) containing constant phase element (CPE) instead of capacitance and charge transfer resistance $\left(\mathrm{R}_{\mathrm{ct}}\right)$, showed excellent agreement with experimental data.

The main parameters deduced from the analysis of Nyquist diagram for $1 \mathrm{M} \mathrm{HCl}$ without and with GL extract is given in Table 3. On increasing GL concentration from $200 \mathrm{mg} / \mathrm{L}$ to $1000 \mathrm{mg} / \mathrm{L}$, the charge transfer resistance $\left(R_{\mathrm{ct}}\right)$ increased and capacitance $\left(C_{\mathrm{dl}}\right)$ decreased indicating that increasing GL concentration decreased corrosion rate. Decrease in the capacitance was caused by reduction in local dielectric constant and/or by increase in the thickness of the electrical double layer. This fact suggests that the inhibitor molecules acted by adsorption at the metal/solution interface [42-44]. On the other hand the decrease in $\mathrm{C}_{\mathrm{dl}}$ with increase in concentration was the result of an increase in the surface coverage by the inhibitor, which led to an increase in the inhibition efficiency. The thickness of the protective layer, $\delta_{\mathrm{org}}$, was related to $C_{\mathrm{dl}}$ by the following equation:

$$
\delta_{\text {org }}=\frac{\varepsilon_{0} \varepsilon_{\mathrm{r}}}{C_{\mathrm{dl}}}
$$

where $\varepsilon_{0}$ is the dielectric constant and $\varepsilon_{\mathrm{r}}$ is the relative dielectric constant. Since adsorption of an organic inhibitor on a metal surface involves the replacement of water molecules and other ions originally adsorbed on the surface, the smaller dielectric constant of organics compared to water as well as the increased thickness of the double layer due to inhibitor adsorption act simultaneously to reduce the interfacial capacitance [45-47]. This provides experimental evidence of adsorption of the extract organic matter on the corroding MS surface.

Table 3. Impedance parameters for mild steel corrosion in $1 \mathrm{M} \mathrm{HCl}$ solution at $303 \mathrm{~K}$ without and with GL extract.

\begin{tabular}{cccccc}
\hline System & $\boldsymbol{R}_{\mathbf{s}}\left(\boldsymbol{\Omega} \mathbf{~ c m}^{\mathbf{2}}\right)$ & $\boldsymbol{R}_{\text {ct }}\left(\boldsymbol{\Omega} \mathbf{~ c m}^{\mathbf{2}}\right)$ & $\boldsymbol{n}$ & $\boldsymbol{C}\left(\boldsymbol{\mu} \mathbf{F} \mathbf{c m}^{-\mathbf{2}}\right)$ & $\mathbf{I E}_{\mathbf{E}} \%$ \\
\hline $1.0 \mathrm{M} \mathrm{HCl}$ & 1.285 & 49.13 & 0.7143 & 72.72 & \\
$50 \mathrm{mg} / \mathrm{L}$ & 1.771 & 87.53 & 0.8151 & 50.70 & 43.87 \\
$200 \mathrm{mg} / \mathrm{L}$ & 1.228 & 262.7 & 0.8852 & 33.33 & 81.29 \\
$400 \mathrm{mg} / \mathrm{L}$ & 5.057 & 357.12 & 0.9273 & 22.12 & 86.21 \\
$1000 \mathrm{mg} / \mathrm{L}$ & 9.661 & 581.7 & 0.9381 & 19.11 & 91.58 \\
\hline
\end{tabular}




\subsubsection{Polarization measurement}

Potentiodynamic polarization curves for $\mathrm{MS}$ in $1 \mathrm{M} \mathrm{HCl}$ solution containing different concentrations of GL extract is shown in Figure 4. It is clear from Figure 4 that both the cathodic anodic reactions are inhibited and the inhibition increased as the inhibitor concentration in acid the media increased. The respective kinetic parameters obtained from Equation 3 are given in Table 4 . The values given in the Table 4 show that the corrosion current $\left(I_{\text {corr }}\right)$ decreased markedly in the presence of extract and the magnitude of change increases with increasing extract concentration. This confirms the inhibitive action of the extract in the $1 \mathrm{M} \mathrm{HCl}$ medium. With increase in plant extract concentration, the corrosion potential $\left(E_{\text {corr }}\right)$ did not vary much. The values of both anodic and cathodic Tafel constants $\beta_{\mathrm{a}}$ and $\beta_{\mathrm{c}}$ respectively are markedly changed in the presence of the extract. This confirms the mixed mode of inhibition of the extract.

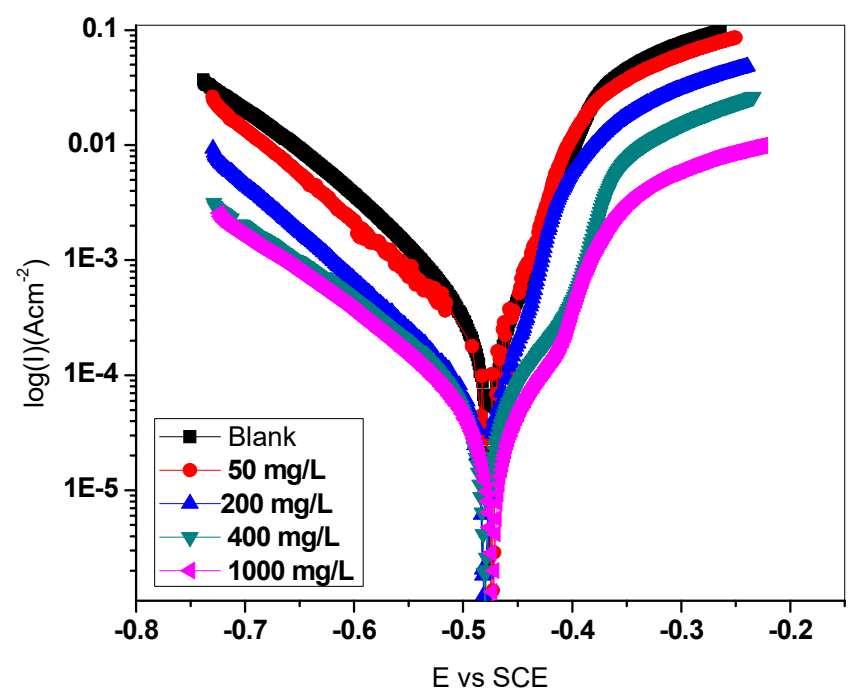

Figure 4. Potentiodynamic polarization curves of mild steel in $1 \mathrm{M} \mathrm{HCl}$ solution without and with GL extract at $303 \mathrm{~K}$.

Table 4. Polarization parameters for mild steel corrosion in $1 \mathrm{M} \mathrm{HCl}$ solution without and with GL extract at $303 \mathrm{~K}$.

\begin{tabular}{cccccc}
\hline System & $\boldsymbol{\beta}_{\mathbf{c}}(\mathbf{m V})$ & $\boldsymbol{\beta}_{\mathbf{a}}(\mathbf{m V})$ & $\boldsymbol{E}_{\mathbf{c o r r}}(\mathbf{m V})$ & $\boldsymbol{I}_{\mathbf{c o r r}}\left(\boldsymbol{\mu} \mathbf{A ~ \mathbf { ~ c m } ^ { - 2 } )}\right.$ & $\mathbf{I E}_{\mathbf{p}} \mathbf{\%}$ \\
\hline $1.0 \mathrm{M} \mathrm{HCl}$ & 110.574 & 49.423 & -475.702 & 204.783 & \\
$50 \mathrm{mg} \mathrm{L}^{-1}$ & 111.414 & 40.126 & -480.831 & 113.839 & 44.40 \\
$200 \mathrm{mg} \mathrm{L}^{-1}$ & 103.252 & 38.902 & -480.519 & 40.502 & 80.22 \\
$400 \mathrm{mg} \mathrm{L}^{-1}$ & 141.955 & 91.092 & -479.918 & 38.666 & 81.12 \\
$1000 \mathrm{mg} \mathrm{L}^{-1}$ & 133.858 & 72.261 & -472.777 & 25.837 & 87.38 \\
\hline
\end{tabular}




\subsection{Adsorption isotherm behaviour}

The interaction between the inhibitors and electrode surface can be described by the adsorption isotherm. During corrosion inhibition of metals and alloys, the nature of the inhibitor on the corroding surface has been deduced in terms of adsorption characteristics of the inhibitor. Furthermore, the solvent $\left(\mathrm{H}_{2} \mathrm{O}\right)$ molecules could also be adsorbed at metal/solution interface. So the adsorption of inhibitor molecules from aqueous solution can be regarded as a quasi-substitution process between the GL extract compounds in the aqueous phase [GLE (sol.)] and water molecules at the electrode surface $\left[\mathrm{H}_{2} \mathrm{O}\right.$ (ads)] [48]:

$$
\mathrm{GLE} \text { (sol.) }+n \mathrm{H}_{2} \mathrm{O} \text { (ads.) }=\mathrm{GLE}(\text { ads. })+n \mathrm{H}_{2} \mathrm{O} \text { (sol.), }
$$

where $n$ is the size ratio, that is, the number of water molecules replaced by one organic inhibitor.

In order to obtain the isotherm, the fractional coverage values $\theta$ as a function of inhibitor concentration must be obtained. In this study, $\theta$ was obtained from impedance data as follows [36, 49]:

$$
\theta=\frac{R_{\mathrm{ct}(\mathrm{inh})}-R_{\mathrm{ct}}}{R_{\mathrm{ct}(\mathrm{inh})}} .
$$

$R_{\mathrm{ct}(\mathrm{inh})}$ and $R_{\mathrm{ct}}$ are defined in Equation 2.

The isotherm that best described the adsorption of the plat extract on the surface of the MS was the Langmuir isotherm. The Langmuir isotherm is based on the assumption that all adsorption sites are equivalent and that particle binding occurs independently from nearby sites, whether occupied or not [50]. According to this isotherm, $\theta$ is related to inhibitor concentration by:

$$
\frac{C_{\text {inh }}}{\theta}=\frac{1}{K_{\text {ads }}}+C_{\text {inh }},
$$

where $K_{\text {ads }}$ is the equilibrium constant of the inhibitor adsorption process and $C_{\text {inh }}$ is the inhibitor concentration.

Straight lines of $C_{\text {inh }} / \theta$ versus $C_{\text {inh }}$ plots indicate that the adsorption of the inhibitor molecules on the electrode surface obeyed Langmuir adsorption model (Figure 5). The regression coefficients of the fitted curves are around unity $\left(R^{2}>0.9993\right)$. The inhibition tendency of the tested inhibitors is due to the adsorption of this molecule on the electrode surface [51]. However, the slope of the $C_{\text {inh }} / \theta$ versus $C$ plot which is close to unity (1.04) indicates the ideal simulating for Langmuir adsorption isotherm. 


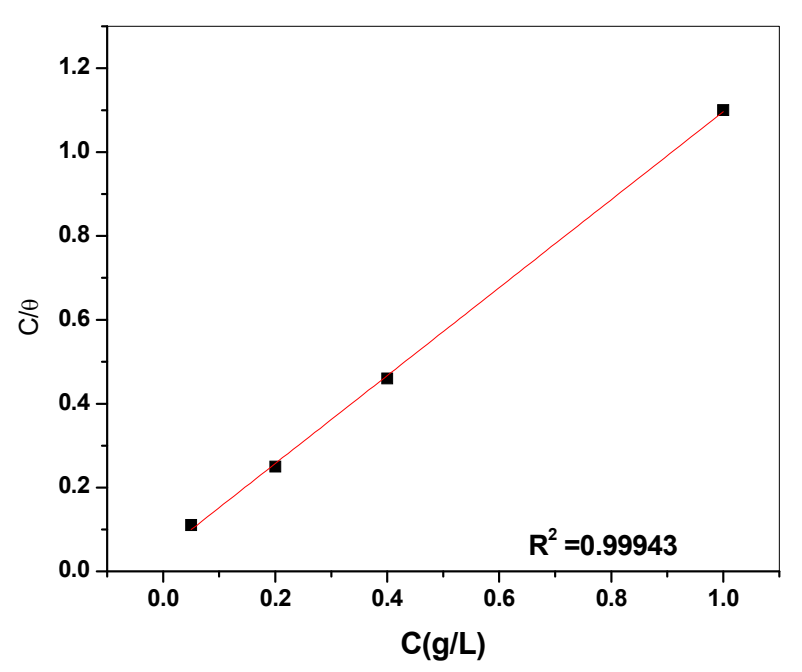

Figure 5. Langmuir adsorption isotherm $\left(C_{\mathrm{inh}} / \theta v s . C_{\mathrm{inh}}\right)$ fitting of the EIS data obtained for mild steel in $1 \mathrm{M} \mathrm{HCl}$ solution containing various concentrations of GL extracts at $303 \mathrm{~K}$.

\subsection{Effect of Temperature}

The change of the corrosion process rate with temperature increase was studied in $1 \mathrm{M} \mathrm{HCl}$ in the absence and in the presence of inhibitor by gravimetric method for $3 \mathrm{~h}$ immersion period. The variation of temperature from $303 \mathrm{~K}$ to $313 \mathrm{~K}$ with IE\% is shown in Figure 6. At $303 \mathrm{~K}$ the inhibition efficiency obtained were 91.1 and $70.1 \%$ in the solution containing 1000 and $50 \mathrm{mg} / \mathrm{L}$ extract, respectively. As the temperature increased, the inhibition efficiency decreased. At 313, 323 and $333 \mathrm{~K}$ maximum inhibition efficiencies were 82.1, 77.0 and $69.3 \%$ for the solution containing $1000 \mathrm{mg} / \mathrm{L}$ and $65.7,63.9$ and $59.5 \%$ for the solution containing $50 \mathrm{mg} / \mathrm{L}$. It is possible the increasing temperature resulted in desorption of some adsorbed phytochemical molecules from the metal surface leading to reduced surface coverage. This observation gives a clue to the type of adsorption.

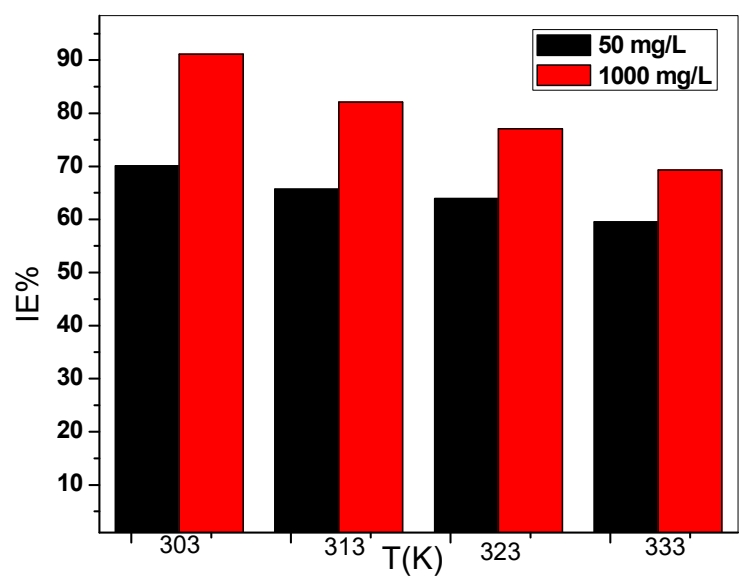

Figure 6. Effect of temperature on inhibition efficiency of GL extract in $1 \mathrm{M} \mathrm{HCl}$ solution. 


\section{Activation energy calculation}

The applicability of the Langmuir isotherm implies that the mode of inhibitory action is, indeed, adsorption. The energy of adsorption, however, could not have been calculated, due to the unknown molecular mass of the extract $[22,42,52]$. Hence, the criterion based on the change of the activation energy in the inhibited system with respect to the uninhibited one, has been applied. It is usually argued that upward or downward changes in activation energy may express physical or chemical bonding [52]. The effective energy of activation $E_{\mathrm{a}}$ was calculated by application of the modified form of the Arrhenius equation [53]:

$$
\log \frac{C_{\mathrm{R}_{2}}}{C_{\mathrm{R}_{1}}}=\frac{E_{\mathrm{a}}}{2.303 R}\left(\frac{1}{T_{1}}-\frac{1}{T_{2}}\right),
$$

where $C_{\mathrm{R}}$ is the corrosion rate at the temperature $T_{1}$ and $T_{2} ; R$ is the universal gas constant; $A$ is the Arrhenius pre-exponential factor. Arrhenius plots for the corrosion rate of mild steel in $1 \mathrm{M} \mathrm{HCl}$ are shown in Figure 6. Values of $E_{\mathrm{a}}$ for mild steel in $1 \mathrm{M} \mathrm{HCl}$ in the absence and presence of different concentrations of GL extract were calculated from the slope of $\log C_{\mathrm{R}}$ versus $1 / 2.303 R T$ plots and given in Table 5. The data shows that the activation energy $\left(E_{\mathrm{a}}\right)$ of the corrosion in mild steel in $1 \mathrm{M} \mathrm{HCl}$ solution in the presence of extract is higher than that in the free acid solution. The increase in the apparent activation energy for mild steel dissolution in inhibited solution may be interpreted as physical adsorption $[54,55]$.

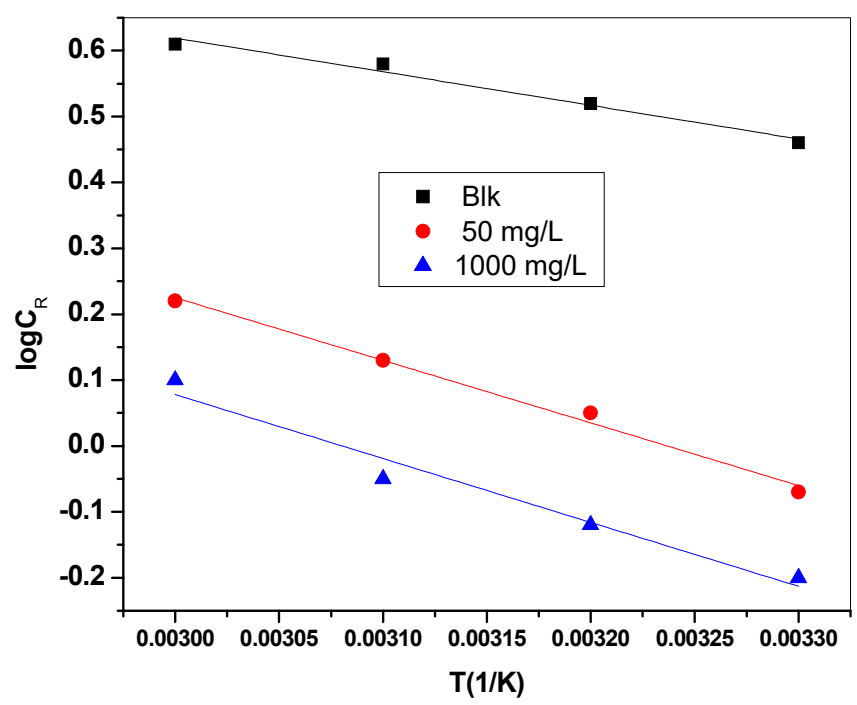

Figure 6. Arrhenius plots for the corrosion rate of mild steel in $1 \mathrm{M} \mathrm{HCl}$ in presence and absence of GL extract. 
Table 5. Values of activation energy $E_{\mathrm{a}}$ for mild steel in $1 \mathrm{M} \mathrm{HCl}$ in the absence and presence of different concentrations of GL.

\begin{tabular}{cc}
\hline System & $\boldsymbol{E}_{\mathbf{a}}(\mathbf{k J} / \mathbf{m o l})$ \\
\hline Blank & 9.77 \\
$50 \mathrm{mg} / \mathrm{L}$ & 18.19 \\
$1000 \mathrm{mg} / \mathrm{L}$ & 18.57 \\
\hline
\end{tabular}

\subsection{Mechanism of inhibition}

As follows from potentiodynamic polarization and EIS measurements, corrosion of the mild steel in $1 \mathrm{M} \mathrm{HCl}$ is retarded in the presence of the GL extract. The results clearly showed that the inhibition mechanism involves blocking of the mild steel surface by inhibitor molecules via adsorption. In general, the phenomenon of adsorption is influenced by the nature of metal and chemical structure of inhibitor. The values of thermodynamic parameters for the adsorption of inhibitors can provide valuable information about the mechanism of corrosion inhibition [56]. As observed earlier, the adsorption mechanism of GL extract on the mild steel surface involves a physisorption. It means that, the GL extract constituents were able to electrostatically adsorb on the steel surface.

Phytochemical and GC-MS analysis of GL extract shows the presence of alkaloids, flavanoids, carbohydrates, phenols, steroids, tannins. These compounds possess hetero atom such as $-\mathrm{N},-\mathrm{O}$, which strengthen adsorptive property over a mild steel surface. The inhibitive influence of these molecules may be attributed to their adsorption through the $-\mathrm{NH}, \mathrm{C}=\mathrm{O}, \mathrm{OH}, \mathrm{COOH}$, etc. groups and also may be because of the presence of $\pi$ electrons in the rings. These organic molecules gets adsorption on the metal surface forming a protective layer and hence the anti-corrosive behaviour [57].

\section{Conclusions}

GL extract acted as an efficient corrosion inhibitor in $1 \mathrm{M} \mathrm{HCl}$. Polarization studies showed that GL extract was a mixed-type inhibitor and its inhibition efficiency increased with the inhibitor concentration. Data obtained from ac impedance technique show a frequency distribution and therefore a modeling element with frequency dispersion behavior, a constant phase element (CPE) has been used. The inhibition efficiencies, calculated from ac impedance study, show the same trend as those obtained from polarization curves measurements. The adsorption of GL extract on the mild steel in $1 \mathrm{M}$ $\mathrm{HCl}$ solution obey Langmuir adsorption isotherm with high correlation coefficient. GL extract remains effective in the all studied temperatures. The thermodynamic parameters obtained reveal a physical adsorption between the GL extract and the metal surface. 


\section{References}

1. R.A. Prabhu, T.V. Venkatesha, A.V. Shanbhag, G.M. Kulkarni and R.G. Kalkhambkar, Corros. Sci., 2008, 50, 3356.

2. N.E. Hamner, Corrosion Inhibitors, ed. C.C. Nathan, NACE Houston, Texas, USA, 1973, p. 1.

3. W.H. Li, Q. He, S. Zhang, C. Pei and B. Hou, J. Appl. Electrochem., 2008, 38, 289.

4. S.A. Ali, H.A. Al-Muallem, S.U. Rahman and M.T. Saeed, Corros. Sci., 2008, 50, 370.

5. S.T. Arab and E.A. Noor, Corrosion, 1993, 49, 122.

6. P. Raja and M. Sethuraman, Mater. Lett., 2008, 62, 2977.

7. Y. Li, P. Zhao, Q. Liang and B. Hou, Appl. Surf. Sci., 2005, 252, 1245.

8. S. Verma and G. N. Mehta, Trans. SAEST, 1997, 32, 4.

9. F.S. de Souza and A. Spinelli, Corros. Sci., 2009, 51, 642.

10. A.Y. El-Etre and Z. El-Tantawy, Port. Electrochim. Acta, 2006, 24, 347.

11. A.M. Abdel-Gaber, E. Khamis, H. Abo-ElDahab and Sh. Adeel, Mater. Chem. Phys., 2008, 109, 297.

12. L.R. Chauhan and G. Gunasekaran, Electrochim. Acta, 2004, 49, 4387.

13. K.O. Orubite and N.C. Oforka, Mater. Lett., 2004, 58, 1768.

14. P. Bothi Raja and M.G. Sethuraman, Mater. Lett., 2008, 62, 113.

15. K. Lakshmi Prabha, Shameela Rajam and B.R. Venkatraman, Der Chemica Sinica, 2012, 3, no. 1, 114.

16. A. Lecante, F. Robert, P.A. Blandinieres and C. Roos, Curr. Appl. Phys., 2011, 11, 714.

17. R.M.H. Lemmens and N. Wulijarni-Soetjipto, Plant Resources of South-East Asia, No. 3: Dye and Tannin-Producing Plants, Pudoc. Wageningen, 1991.

18. P. B. Raja and M. G. Sethuraman, Mater. Lett., 2008, 62, 113.

19. K.B. Magarea and B.M. Ubaleb, Der Chemica Sinica, 2011, 2, no. 2, 158.

20. M. Yadaz, D. Behera and U. Sharma, Der Chemica Sinica, 2012, 3, no. 1, 262.

21. O. Blajiev and A. Hubin, Electrochim. Acta, 2009, 49, 2761.

22. L. Valek and S. Martinez, Mater. Lett., 2007, 61, 148.

23. A.F. Eleyimi, J. Zhejiang Univ Sci B., 2007, 8, no. 5, 352 . doi: 10.1631/jzus.2007.B0352

24. N.H. Ugochukwu and N.E. Babady, Fitoterapia, 2002, 73, no. 7-8, 612. doi: 67326x(02)00218-6

25. N.H. Ugochukwu, N.E. Babady, M. Cobourne and S.R. Gasset, J. Biosci. (New Delhi, India), 28, 1.

26. C. Schneider, K. Rotscheidt and E. Breitmaier, Liebigs Ann. Chem., 1993, 10, 1057.

27. O. Morebise and M.A. Fafunso, Biokemistry, 1998, 8, no. 2, 69.

28. O.O. Ogundipe, J.O. Moody, T.O. Akinyemi and A. Raman, Plant Foods Human Nutri, 2003, 58, no. 3, 1 . 
29. A. Sofowora, Medicinal plants and Traditional Medicine in Africa, Spectrum Books, Ibadan, 1993, p. 150.

30. G.E. Trease and W.C. Evans, Pharmacognosy, 13th ed., Bailliere Tindall, London, 1989, p. 176.

31. J.B. Harbone, Phytochemical Methods, 3rd ed., Chapman and Hall, London, 1978.

32. J.T. Wabanne and V.I. Okafor, J. Emerging Trends Eng. Appl. Sci., 2011, 2, 619.

33. V.I. Okafor and E.E. Ebenso, Pigm. Resin Technol., 2007, 36, 299.

34. A. Ostovari, S.M. Hoseinieh, M. Peikari, S.R. Shadizadeh and S.J. Hashemi, Corros. Sci., 2009, 51, 1935.

35. J.R. Macdonald, Impedance Spectroscopy, John Wiley and Sons, 1987.

36. A. Popova, M. Christov, A. Vasilev and Chr. Girginov, Int. J. Corros. Scale Inhib., 2015, 4, no. 4, 382. doi: $10.17675 / 2305-6894-2015-4-4-7$

37. Z. Stoynov, Electrochim. Acta, 1990, 5, 149.

38. F.B. Growcock and J.H. Jasinski, J. Electrochem. Soc., 1989, 136, 3210.

39. A. Popova, Corros. Sci., 2007, 49, 2144.

40. H. Ma, X. Cheng, G. Li, S. Chen, Z. Quan, S. Zhao and L. Niu, Corros. Sci., 2000, 42, 1669.

41. D. Seifzadeh and Z. Rajabalizadeh, Surf. Coat. Technol., 2013, 128, 119.

42. J.C. Da Rocha, J.A. Da Cumha Ponciano Gomes and E. D'Elia, Corros. Sci., 2010, 52, 2341.

43. H.A. Sorkhabi, B. Shaabani and D. Seifzadeh, Electrochim. Acta, 2005, 50, 3446.

44. M. Lebrini, F. Robert, A. Lecante and C. Roos, Corros. Sci., 2010, 53, no. 2, 687. doi: 10.1016/j.corsci.2010.10.006

45. S. Muralidharan, M.A. Quraishi and S.V.K. Iyer, Corros. Sci., 1995, 37, no. 11, 1739.

46. A. Singh, A. Kumar and M.A. Quraishi, The Open Electrochem. J., 2010, 2, 43.

47. A. Lecante, F. Robert, P.A. Blandinières and C. Roos, 2011, Curr. Appl. Phys., 11, 714.

48. I.T. Ismayilov, H.M. Abd El-Lateef, V.M. Abbasov, E.N. Efremenko, L.I. Aliyeva and Ch.K. Salmanova, Int. J. Corros. Scale Inhib., 2015, 4, no. 1, 57. doi: 10.17675/23056894-2015-4-1-057-074

49. M. Lebrini, F. Robert, A. Lecante and C. Roos, Corros. Sci., 2011, 53, no. 2, 687.

50. R. Solmaz, G. Kardas, M. Culha, B. Yazici and M. Erbil, Electrochim. Acta, 2008, 53, 5941.

51. I.B. Obot and N.O. Egbedi, Port. Electrochim. Acta, 2009, $27,517$.

52. S. Martinez and I. Stagljar, J. Mol. Struct.: THEOCHEM, 2003, 640, 167.

53. Lj.M. Vračar and D.M. Dražić, Corros. Sci., 2002, 44, 1669.

54. A.K. Satapathy, G. Gunasekaran, S.C. Sahoo, Kumar Amit and P.V. Rodrigues, Corros. Sci., 2009, 51, 2848.

55. F.S. de Souza and A. Spinelli, Corros. Sci., 2009, 51, 64.

56. A. Popova, E. Sokolova, S. Raicheva and M. Christov, Corros. Sci., 2003, 45, 33. 
57. F. Bentiss, M. Lebrini and M. Lagrenée, Corros. Sci., 2005, 47, 2915.

58. N. Nair Rekha, I.K. Sashi Sharma, P.S. Sharma and A.S. Verma, Rasyan J. Chem., 2010,3 , no. 4,783 . 